\title{
OCULAR PERFORATION DURING PERIBULBAR ANAESTHESIA
}

\author{
J. T. GILLOW, R. K. AGGARWAL and G. R. KIRKBY \\ Birmingham
}

\begin{abstract}
SUMMARY
Six cases of ocular perforation after peribulbar anaesthesia are reported. They were referred to our vitreoretinal unit from other hospitals over a 6 week period. Some recent reports of ocular perforation with peribulbar anaesthesia suggest a good prognosis. In this series all six required surgical intervention and most cases associated with a retinal detachment had a poor outcome. This study highlights the dangers of ocular perforation and emphasises the need for supervised training of peribulbar anaesthesia and early referral should ocular perforation occur.
\end{abstract}

Ocular perforation is a well-recognised but uncommon complication of peribulbar anaesthesia. We present a series of six patients referred from other hospitals to our vitreo-retinal unit between 19 December 1994 and 25 January 1995. We document their progress and visual outcome.

\section{METHODS}

During a 6 week period six patients were referred with ocular perforation resulting from peribulbar anaesthesia. These were followed prospectively, recording the treatment they required and the visual outcome.

All patients had peribulbar anaesthetics administered by consultant anaesthetists. Details of the anaesthetic technique used were obtained from the referring surgeon, who, if necessary consulted with his or her anaesthetic colleague. In every case a twoinjection peribulbar technique had been used, with the first injection given at the lateral third of the lower orbital rim via a transcutaneous approach. A second injection was given either at the medial third of the upper orbital rim through the upper lid using the standard peribulbar technique described by Davis and Mandel, ${ }^{1}$ or alternatively by an injection

Correspondence to: Timothy Gillow, MRCP, FRCOphth, Birmingham and Midland Eye Centre, Dudley Road, Birmingham B18 7QH, UK at the inner canthus. In all cases a $25 \mathrm{~mm} 25$ gauge sharp needle was used. The ocular perforation was not noticed at the time of administration of the local anaesthesia and all operations proceeded without further complication.

\section{RESULTS}

Of the six patients sustaining ocular perforation from local anaesthesia there were four women and two men with ages ranging from 71 to 81 years (mean 76 years). All had undergone peribulbar blocks. Five underwent cataract surgery and one trabeculectomy. Axial lengths of the operated eyes ranged from 21.53 to $25.10 \mathrm{~mm}$ (mean $23.35 \mathrm{~mm}$ ). The peribulbar blocks were all given by consultant anaesthetists. The results of the six cases are presented (Table I).

The surgical techniques required to treat the patients varied according to the site of perforation, severity of retinal detachment and associated proliferative vitreoretinopathy (PVR). Three cases are presented for their surgical interest.

\section{Patient 1}

A 78-year-old woman with a dense left cataract and pre-operative visual acuity of $6 / 60$ underwent extracapsular cataract surgery. A vitreous haemorrhage was noted on the first post-operative day, the retina was recorded as flat and the surgeon considered that the haemorrhage was old. At referral on the 36th post-operative day the vision was hand movements and there was a sub-total retinal detachment with PVR stage CP 4 (updated Retina Society Classification) (Fig. 1). At surgery a posterior perforation site near the optic disc was seen but no anterior perforation site was identifiable. After vitrectomy, membrane peel, silicone oil and encirclement the retina was anatomically flattened (Fig. 2). Corrected visual acuity at 1 year was $6 / 60$.

\section{Patient 2}

A 71-year-old man with pre-operative visual acuity 
Table I. Patient details

\begin{tabular}{|c|c|c|c|c|c|c|}
\hline & Patient 1 & Patient 2 & Patient 3 & Patient 4 & Patient 5 & Patient 6 \\
\hline $\begin{array}{l}\text { Age (years) } \\
\text { Axial length (mm) } \\
\text { Pre-op. VA } \\
\text { Days to referral }\end{array}$ & $\begin{array}{l}78 \\
21.53 \\
\mathrm{HM} \\
36\end{array}$ & $\begin{array}{l}71 \\
23.93 \\
6 / 6 \\
57\end{array}$ & $\begin{array}{l}73 \\
22.74 \\
\mathrm{HM} \\
21\end{array}$ & $\begin{array}{l}81 \\
22.98 \\
6 / 60 \\
36\end{array}$ & $\begin{array}{l}79 \\
25.10 \\
\text { PL } \\
72\end{array}$ & $\begin{array}{l}79 \\
23.65 \\
\mathrm{HM} \\
12\end{array}$ \\
\hline $\begin{array}{l}\text { Findings } \\
\text { Vitreous haemorrhage } \\
\text { Perforation sites }\end{array}$ & $\begin{array}{l}\text { Yes } \\
\text { Temporal to } \\
\text { optic disc }\end{array}$ & $\begin{array}{l}\text { Yes } \\
\text { Superior }\end{array}$ & $\begin{array}{l}\text { Yes } \\
\text { Temporal and } \\
\text { superotemporal } \\
\text { macula }\end{array}$ & $\begin{array}{l}\text { Yes } \\
\text { Inferotemporal } \\
\text { and inferior } \\
\text { macula }\end{array}$ & $\begin{array}{l}\text { Yes } \\
\text { Temporal and } \\
\text { fovea }\end{array}$ & $\begin{array}{l}\text { Yes } \\
\text { Temporal }\end{array}$ \\
\hline Retinal detachment & Sub-total & Inferior bullous & Nil & Total & Total & Temporal \\
\hline VA at 1 year & $\begin{array}{l}\text { Vitrectomy, } \\
\text { membrane peel, } \\
\text { silicone oil, } \\
\text { encirclement } \\
6 / 60\end{array}$ & $\begin{array}{l}\text { Vitrectomy, } \\
\text { encirclement, } \\
\text { gas } \\
6 / 9\end{array}$ & Vitrectomy & $\begin{array}{l}\text { Vitrectomy, } \\
\text { membrane peel, } \\
\text { silicone oil }\end{array}$ & $\begin{array}{l}\text { Vitrectomy } \\
\text { (inoperable) }\end{array}$ & $\begin{array}{l}\text { (i) Vitrectomy } \\
\text { gas } \\
\text { (ii) Retinectomy } \\
\text { silicone oil } \\
\text { NPL }\end{array}$ \\
\hline
\end{tabular}

of $6 / 6$ underwent trabeculectomy. Vitreous haemorrhage was noted on the first post-operative day.

Two weeks post-operatively two linear scars were noted superiorly and identified as needle injury sites

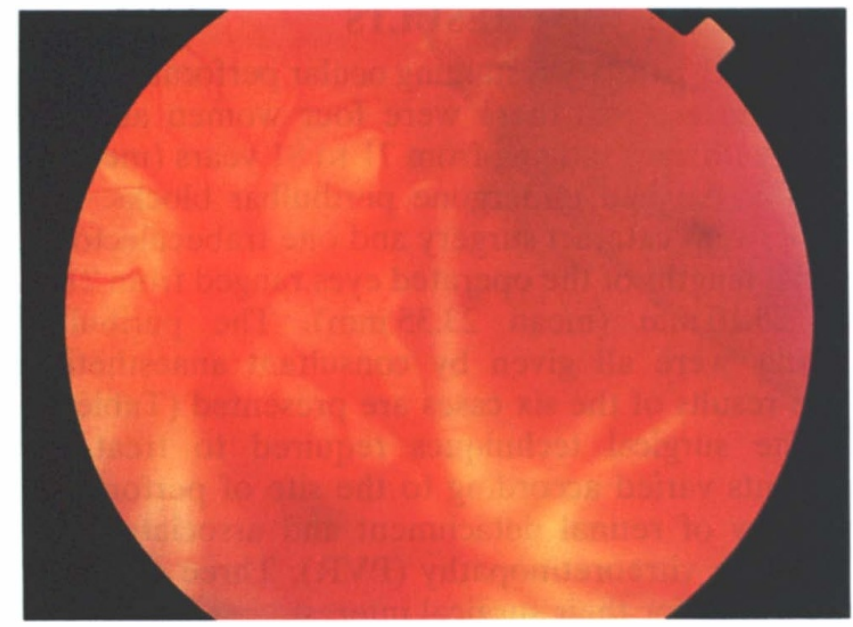

Fig. 1. Patient 1. Fundal photograph at referral taken through the remaining vitreous haemorrhage showing the retinal star folds and obscuration of the optic disc.

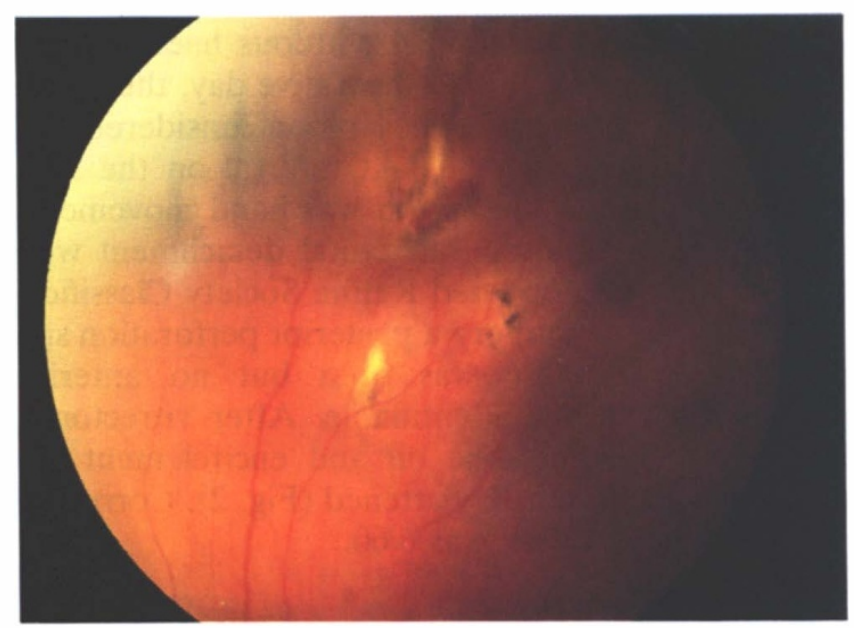

Fig. 3. Patient 2. Retinal pigment epithelial scars at sites of scleral perforation. There is a full-thickness oval retinal hole just below upper white scar.
(Fig. 3). The retina remained flat and visual acuity $6 / 6$. On day 57 a retinal detachment was noted and the patient was referred. A retinal 'U-tear' well away from the perforation site was identified and the

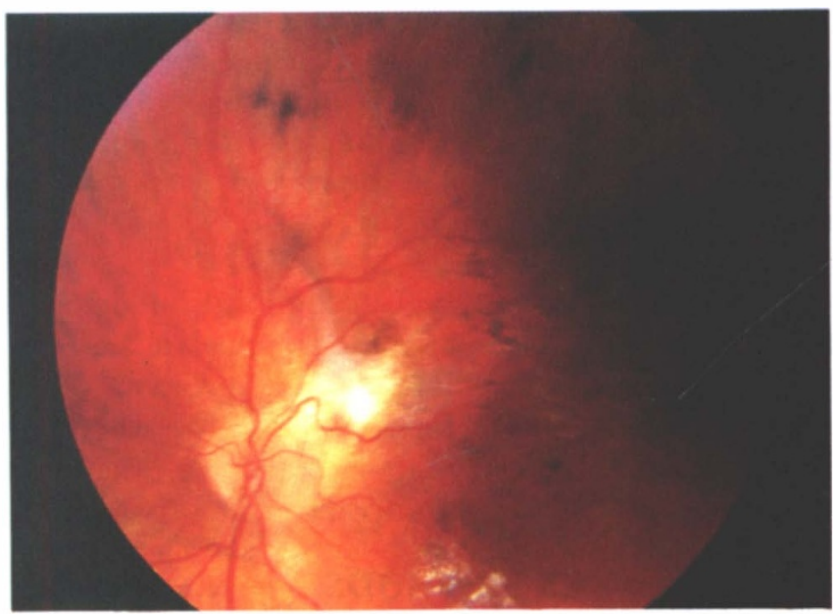

Fig. 2. Patient 1. The same eye as in Fig. 16 months after surgery. The posterior needle exit site scar lies near the optic disc. The posterior pole remains flat with silicone oil in situ.

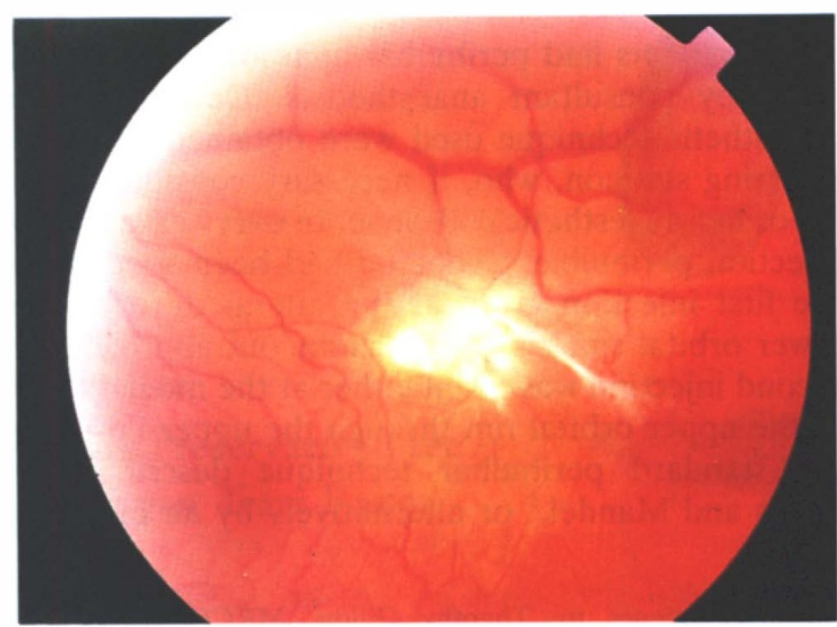

Fig. 4. Patient 3. The needle exit site is below the superotemporal arcade. 
retina in the area of the needle perforation remained flat. The 'U-tear' occurred in association with lattice degeneration. A further tear was discovered at operation in the inferior retina obscured by vitreous haemorrhage. The development of retinal detachment in this case is attributed to the development of a posterior vitreous detachment following intravitreal bleeding. The patient underwent vitrectomy, internal fluid $/ 25 \%$ sulphur hexafluoride gas exchange, and encirclement. Corrected visual acuity at 1 year was 6/9.

\section{Patient 3}

A 73-year-old woman with a left cataract and preoperative visual acuity of $6 / 24$ underwent extracapsular cataract surgery. On the first post-operative day there was a dense vitreous haemorrhage obscuring the fundal view. B-scan ultrasonography demonstrated a flat retina and a complete posterior vitreous detachment. The patient was referred on day 21 when the vision was hand movements. The vitreous haemorrhage was removed by vitrectomy, revealing a pre-equatorial needle entry site and a posterior exit site. The exit site (Fig. 4) lay below the superotemporal arcade. After surgery the retina remained flat and corrected visual acuity at 1 year was 6/12-2. Visual field examination revealed an arcuate defect corresponding to axonal disruption by the needle tip.

\section{DISCUSSION}

The classic peribulbar technique as described by Davis and Mandel $^{1}$ requires two injections: one at the lateral third of the lower orbital rim and the second at the medial third of the upper orbital rim. It was introduced as an attempt to reduce the complications associated with retrobulbar anaesthesia, including ocular perforation. Many of the reported cases of ocular perforation occurring after local anaesthesia have occurred with retrobulbar anaesthesia ${ }^{2-5}$ and perforation, although reported, ${ }^{5-8}$ appears to be less common with the peribulbar technique. Davis and Mandel $^{9}$ emphasise the safety of peribulbar anaesthesia in skilled hands, and in their series of 16224 consecutive peribulbar blocks report a single globe perforation ( $0.006 \%$ incidence).

This series of cases demonstrates the serious consequences of ocular perforation by the local anaesthetic needle during peribulbar anaesthesia and raises important issues in the prevention and appropriate management of such cases. Contrary to some of the previously reported series ${ }^{6,7}$ the visual outcome of our group has been poor in four of the six patients. The lessons which can be learnt from this report will, we hope, reduce the risk of similar tragedies occurring in the future.

In patients undergoing surgery with peribulbar or retrobulbar anaesthesia a diagnosis of ocular per- foration must be entertained if vitreous haemorrhage is apparent on the first post-operative day. In only one of the six cases in this series was ocular perforation seriously considered as a diagnosis by the original surgeon from day 1 post-operatively. Four cases had been labelled as post-operative vitreous haemorrhage of unestablished cause and in the one case a diagnosis of branch retinal vein occlusion had been made. The delay in referral to the vitreo-retinal unit ranged from 12 to 72 days (mean 48 days).

If a retinal break is identified and the surrounding retina remains flat, prophylactic laser photocoagulation or cryotherapy around the break is associated with a good outcome. ${ }^{2}$ Retinal detachments following peripheral perforations are associated with a better outcome if treated early whilst the detachment remains shallow, localised and away from the macula. In three of the cases in this series referral occurred late when the macula was detached, the detachment was bullous and PVR had supervened.

The site of perforation was a major factor affecting outcome in the series. In four of the six cases an exit site retinal perforation was seen at the posterior pole, suggesting a probable double perforating injury. Double perforating injuries in other traumatic cases are known to have a worse prognosis. ${ }^{10}$ The resulting retinal pathology with posterior retinal breaks required complex surgical intervention. This is in marked contrast to previous reports, ${ }^{2,6,7}$ where perforations are described as peripheral or equatorial linear lines.

In all invasive procedures it is clearly essential that thorough training is accompanied by careful supervision during initial practice. Until recently most local anaesthesia was given by ophthalmic surgeons. However, recent changes in the West Midlands, as elsewhere in the United Kingdom, have resulted in a large increase in the numbers of anaesthetists performing peribulbar anaesthesia. In ocular anaesthesia knowledge of the orbital anatomy and possible complications together with their signs and symptoms is essential. This series provides further evidence that changes in practice must be accompanied by adequate training and supervision.

In conclusion, it is evident that those performing peribulbar anaesthesia must have proper training and supervision during early clinical experience. A high complication rate may occur if this is deficient. Ocular perforation should be suspected when fresh vitreous haemorrhage is noted on the first postoperative day. Close follow-up and early appropriate intervention for associated complications is recommended in order to achieve the best visual outcome. The generally poor outcome in this series contrasts with the results from some other series ${ }^{6,7}$ and can be 
attributed to the nature of the perforations and late referral for vitreo-retinal intervention. We advise early referral of all suspected cases, especially those with dẹnse vitreous haemorrhage preventing a clear view of the retina.

Key words: Cataract extraction, Ocular perforation, Peribulbar.

\section{REFERENCES}

1. Davis DB, Mandel MR. Posterior peribulbar anaesthesia: alternative to retrobulbar anaesthesia. J Cataract Refract Surg 1986;12:182-4.

2. Rinkoff JS, Doft BH, Lobes LA. Management of ocular penetration from injection of local anesthesia preceding cataract surgery. Arch Ophthalmol 1991; 109:1421-5.

3. Duker JS, Belmont JB, et al. Inadvertent globe perforation during retrobulbar and peribulbar anaesthesia. Ophthalmology 1991;98:519-26.

4. Boniuk V, Nockowitz R. Perforation of the globe during retrobulbar injection: medicolegal aspects of four cases. Surv Ophthalmol 1994;39:141-5.

5. McCombe M, Heriot W. Penetrating ocular injury following local anaesthesia. Aust NZ J Ophthalmol 1995;23:33-6.

6. Mount AM, Seward HC. Scleral perforations during peribulbar anaesthesia. Eye 1993;7:766-7.

7. Kimble JA, Morris RE, Witherspoon CE, Feist RM. Globe perforation from peribulbar injection. Arch Ophthalmol 1987;105:749.

8. Joseph JP, McHugh JD, Franks WA, Chignell AH. Perforation of the globe: a complication of peribulbar anaesthesia. Br J Ophthalmol 1991;75:504-5.

9. Davis DB, Mandel MR. Efficacy and complication rate of 16224 consecutive peribulbar blocks: a prospective multicenter study. J Cataract Refract Surg 1994;20: 327-37.

10. De Juan E, Sternberg P, Michaels RG. Penetrating ocular injuries: types of injury and visual results. Ophthalmology 1983;90:1318-22. 